Zbigniew Bierzyński*

\title{
TRZY MIGRACJE. ZARYS POCZĄTKÓW BUDDYZMU W TYBECIE I JEGO WPEYWU NA KULTURĘ TYBETAŃSKĄ ZE SZCZEGÓLNYM UWZGLĘDNIENIEM KONCEPCJI STRAŻNIKÓW DHARMY
}

\section{Wstęp}

Teza, że buddyzm ukształtował i kształtuje kulturę Tybetu wydaje się trywialna i oczywista. Niemniej w niniejszym artykule zinterpretowano to założenie przez pryzmat tytułowej migracji rozumianej dosłownie i metaforycznie. Przez omówienie początków buddyzmu w Himalajach podjęto również próbę przybliżenia jednego z fenomenów tradycji tybetańskiej - dharmapala, czyli Strażników Dharmy, którzy niejednokrotnie ukazywani są w formie tzw. gniewnych bóstw, co może wywoływać konsternację u Europejczyka kierującego się stereotypowym wyobrażeniem Buddy.

W pierwszej części niniejszego artykułu przedstawiono migrację buddyzmu na dach świata i skutki, jakie za sobą pociągnęła. W drugiej części natomiast omówiono szczegółowiej jeden z tych skutków, czyli ideę Strażników Dharmy. W końcu w trzeciej części przedstawiono pokrótce współczesną migrację Tybetańczyków z zajętego przez Chińczyków Tybetu, co z pewnością stanowi punkt wyjścia dla dalszych refleksji i pogłębionych badań nad duchowością współczesnego pokolenia emigrantów.

Na zakończenie tego wstępu warto jeszcze zaznaczyć, że w tekście podano w nawiasach kwadratowych transliterację nazw i imion pochodzenia tybetańskiego według Turrella Wyliego oraz że w artykule znalazły się cztery thanki ${ }^{1}$ postaci omawianych w tekście.

* Mgr Zbigniew Bierzyński, Uniwersytet Łódzki.

1 Malowane zwykle na bawełnianym płótnie przedstawienia bóstw i świętych. Więcej o thankach zob. Brauen, Martin, Was sind Thangkas?, http://www.thangka.de/Icono /thangkasgerm.htm [Dostęp: 26.04.2019]. 


\section{Pierwsza migracja - buddyzm wkracza do Tybetu}

Według kronik w roku 637 tybetański król Songcena Gambo [Srong-bcan-sgam-po] poślubił księżniczkę Bhrikuti z Nepalu, która przywiozła ze sobą posąg Buddy, umieszczony później w świątyni Ramocze [Ra-mo-che]. Cztery lata później władca poślubił chińską księżniczkę Wen Cz’eng, która również przywiozła ze sobą wizerunek Oświeconego zwany Dżobo Rinpocze [Jo-bo Rin-po-che], stojący do dziś w najważniejszej lhaskiej świątyni - Dżokhang [Jo-khang]. Posąg stał się z czasem najsłynniejszym i najświętszym z tybetańskich wizerunków Śakjamuniego (Uhlig 2008: 54, 63). Wtedy król Himalajów nawrócił się na buddyzm, a tym samym rozpoczął się okres krzewienia nowej tradycji na obszarze całego państwa (Uhlig 2008: 63). To właśnie dzięki przychylnej postawie panującego w latach od ok. 620 do 649 Songcena Gambo [Srong-bcan-sgam-po], jego dwóch żon oraz dzięki działalności guru Padmasambhawy buddyzm znalazł dogodne warunki rozwoju na dachu świata.

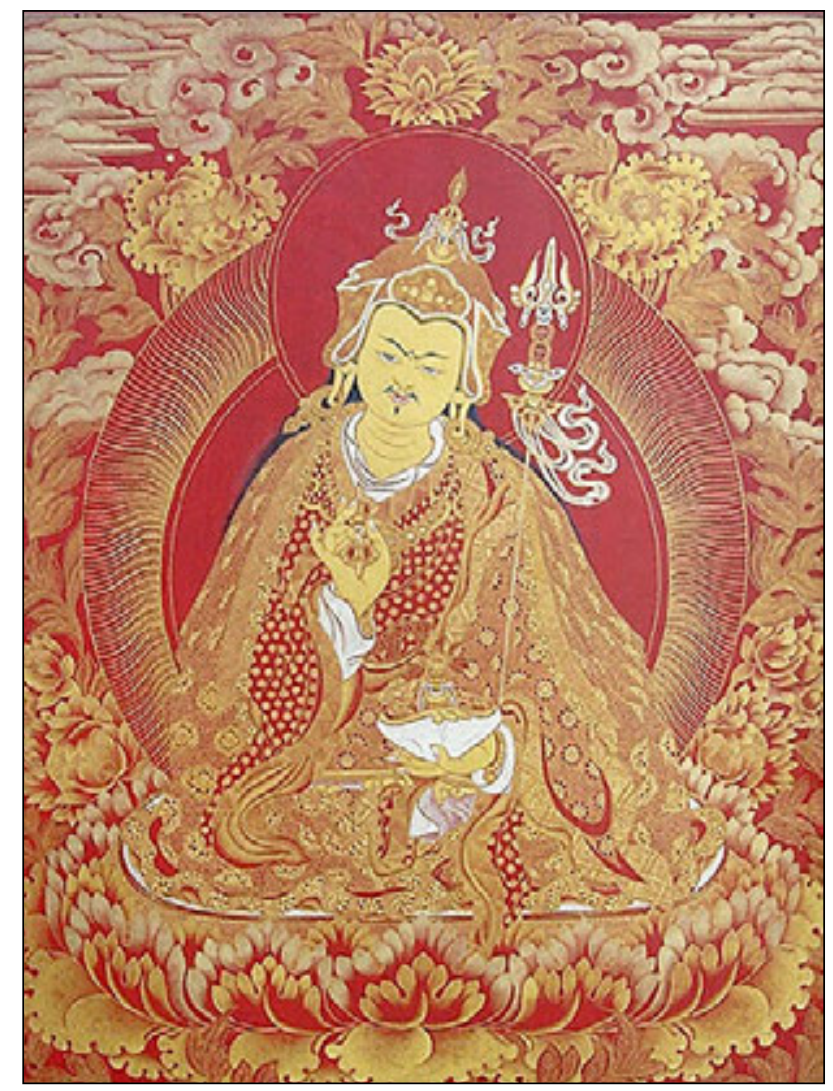

Thanka nr 1, Guru Padmasambhawa,

http://www.thangka.de/Gallery-3/Padma/11-1/Padma-1.htm [Dostęp: 20.04.2019] 
Bardzo znaczącymi wydarzeniami w migracji buddyzmu były budowy dwóch wspomnianych wyżej świątyń. W tym miejscu wkraczamy w uniwersum, w którym fakty historyczne splatają się z legendami. Na płaszczyźnie faktów Ramocze [Ra-mo-che] powstało z inicjatywy chińskiej żony króla ok. VII wieku. Miał to być pomnik jej wierności wobec Dharmy ${ }^{2}$ oraz symbol oporu stawionego himalajskim demonom i szamańskim praktykom. Z kolei według podań przybytek wzniesiono w miejscu altany, którą Wen Cz’eng wybudowała na północ od pałacu, by zdjąć urok rzucony na władcę. Przez dwa lata śpiewała smutne pieśni, zamieszkując to prowizoryczne schronienie, aż w końcu król usłyszał jej głos, a klątwa została przezwyciężona. Wen Cz’eng została królową, a kraj otworzył swoje podwoje na jej wiarę (Uhlig 2008: 62-63).

Także historia powstania Dżokhangu [Jo-khang] splata się z legendami. Według nich demoniczne moce zamieszkujące podmokły teren budowy przeszkadzały przy wzniesieniu świątyni, ustawicznie niszcząc kamień węgielny. W celu przebłagania duchów Songcen Gambo [Srong-bcan-sgam-po] wrzucił do jeziora swój własny pierścień. W jego ślady poszli następnie dygnitarze i szlachta. Później władca i poddani złożyli uroczyste ślubowanie wzniesienia przybytku mimo wszelkich przeciwności. Zebrani nad brzegiem poczęli wrzucać do wody kamienie, które uformowały trwałe podłoże. Długa legenda obfituje w szczegóły całego przedsięwzięcia, w tym przeprowadzonych ceremonii, które miały zażegnać opór sił nadprzyrodzonych (Uhlig 2008: 78-80).

Wyżej przytoczone mity obrazują w baśniowy sposób walkę, jaką napływowy buddyzm musiał stoczyć z rodzimą tradycją - szamanizmem bon [bon], wokół którego koncentrował się opór konserwatywnych przeciwników króla patronującego obcej religii.

W migracji Buddy na dach świata znaczącą rolę odegrał wspomniany wcześniej guru Padmasambhava, zakładając pierwszy w Tybecie klasztor buddyjski Samje [bSam-yas] ok. 779 roku. Klasztor otrzymał od króla T’isonga Decena [K'ri-srong-lde-brtsan] ziemię, która nie podlegała odtąd państwowej administracji i od której nie podbierano danin. Podstawa nowej gospodarki uprzywilejowywała takie ośrodki jak Samje [bSam-yas], tym samym nakładając dotkliwe obciążenia na chłopów troszczących się o wyżywienie i ubiór mnichów. Na przykład tylko przeor Samje [bSam-yas] otrzymywał rocznie dziewięć sztuk ubrania, jednego konia, 75 miar jęczmienia, 1100 uncji korzennego masła oraz papieru i atramentu (Uhlig 2008: 109-110). Choć klasztory stały się feudalnym ciężarem, były również ośrodkami kultury i nauki, oferującymi możliwość kariery w strukturach administracji państwowej i religijnej.

${ }^{2}$ Dharma (z sanskrytu) to nauka Buddy. By odróżnić to słowo od rzeczownika pospolitego oznaczającego rzecz, przedmiot, zapisuje się je dużą literą (Tokarska-Bakir 2014: 248). 
Migracja buddyzmu do Tybetu nie pociągnęła za sobą tylko nowych stosunków gospodarczych. W roku 632 Songcen Gambo [Srong-bcan-sgam-po] wysłał swojego ministra T'on-mi Sambhotę do Indii, by przywiózł z kolebki nowej wiary teksty i święte wizerunki do studiowania. Podróż zaowocowała powstaniem pisma tybetańskiego opartego na jednym z pism guptyjskich (Uhlig 2008: 17).

Na zakończenie warto wspomnieć o politycznych nadziejach pokładanych w buddyzmie, który miał umożliwić Songcenowi Gambo [Srong-bcan-sgam-po] - podobnie jak indyjskiemu Aśoce w III wieku, ustabilizowanie sytuacji wewnętrznej w kraju po sukcesach militarnych w Chinach. Jest to bowiem okres rodzącego się imperium tybetańskiego potrzebującego idei spajającej wieloetniczne terytorium (Uhlig 2008: 83-84).

Podsumowując pierwszą część, migracja buddyzmu zmieniła stosunki gospodarczo-społeczne, przyczyniła się do rozwoju kultury i otworzyła nowy rozdział w dziejach Tybetu. Kolejnym krokiem była rozprawa z opozycją skoncentrowaną wokól szamanów bon [bon].

\section{Druga migracja - demony udają się do klasztorów}

Korzeni Strażników Dharmy należy szukać w działalności guru Padmasambhawy, który został zaproszony do Tybetu przez króla T'isonga Decena [K'ri-srong-lde-brtsan]. Imperium obejmowało wówczas całą Azję Środkową, północne Indie, Zatokę Bengalską, Kaszmir, dzisiejszy Pakistan, część Afganistanu aż po Kabul i Turkmenistan wschodni. W centrum rozległego kraju spierały się dwie siły - buddyjska i szamanistyczna bon [bon]. Według legend zadaniem guru Padmasambhawy było wygnanie demonów zagrażających spokojowi wewnętrznemu państwa. Tutaj ponownie wkraczamy w świat, w którym mity i fakty wzajemnie się przeplatają. W rzeczywistości bowiem chodziło o ujarzmienie konserwatywnej opozycji skupionej wokół starej wiary, która chciała odebrać buddyzmowi uprzywilejowaną pozycję, a tym samym podważyć prymat rządzącej dynastii (Uhlig 2008: 88-89).

Wiadomo, że Padmasambhawa wywiązał się ze swojego zadania, obłaskawiając groźne duchy bonu [bon], które następnie uroczyście wprowadzono do Dżokhangu [Jo-khang], przydzielając im funkcję protektorów napływowej wiary. Ukoronowaniem triumfu nowej tradycji było ustanowienie buddyzmu religią państwową w roku 779 (Uhlig 2008: 88-89).

Zaprzysiężenie szamanistycznych duchów Buddzie stało się jedną ze specyficznych cech tradycji buddyzmu tybetańskiego. W tym miejscu konieczna jest jego krótka prezentacja umożliwiająca zrozumienie natury Strażników Dharmy.

Buddyzm tybetański określa się jako tantryczny lub buddyzm wadżrajany (Diamentowy Wóz). Oba pojęcia są ze sobą ściśle powiązane (Tokarska-Bakir 2014: 254). Dalajlama XIVi Jinpa (2015: 39) definiują tantrę jako „zaawansowany 
system filozofii i praktyk [...]. Tantra dosłownie znaczy kontinuum, czy też linia przekazu. Tekst z tradycji joga tantry [...] wyjaśnia, iż tantra odnosi się głównie do kontinuum umysłu czy też świadomości”.

Warto naświetlić w tym miejscu także już pokrótce wyjaśnioną wyżej etymologię samego terminu tantra, który wywodzi się z sanskrytu i oznacza ponadto tkaninę, związek, zależność (Uhlig 2008: 31).

By zrozumieć drugie pojęcie - wadżrajana, należy przybliżyć klasyczny podział buddyzmu na trzy pojazdy. Pierwszy z nich to hinajana (Mały Wóz), czyli praktyki wiodące do indywidualnego Oświecenia (Dalajlama XIV; Jinpa 2015: 22). Drugi to mahajana (Wielki Wóz), czyli pojazd uniwersalny, praktyki wiodące do Oświecenia samego siebie oraz wszystkich żywych i czujących istot (Dalajlama XIV; Jinpa 2015: 34). Najbardziej zaawansowanym jest właśnie Pojazd Diamentowy.

Zwiera się w nim [...] pojazd tantryczny, czyli wadżrajana, w tradycji tybetańskiej uważana za najbardziej zaawansowany. Oprócz praktyk medytacyjnych, $[\ldots]$ jego elementami są ponadto określone zaawansowane techniki, wykorzystujące w praktyce medytacyjnej różne części ciała fizycznego. Poprzez [...] subtelną i umiejętną koordynację ciała i umysłu praktykujący jest w stanie przyspieszyć proces odcinania korzenia niewiedzy i całkowitej eliminacji jego skutków i śladów. Kulminacją jest osiągnięcie pełnego przebudzenia. Opisywany aspekt - angażowanie się w praktyki medytacyjne, które polegają na subtelnej koordynacji umysłu i ciała praktykującego - jest unikatową cechą pojazdu tantry (Dalajlama XIV; Jinpa 2015: 23).

$\mathrm{W}$ przytoczonym cytacie tantra utożsamiona zostaje $\mathrm{z}$ wadżrajaną. Jest narzędziem angażującym praktykującego w pełni - jego stronę umysłową i fizyczną lub, mówiąc inaczej, uwzględniającym związek (zależność), jaki zachodzi między ciałem a umysłem. Buddyzm tybetański polega więc w swoich najbardziej wyrafinowanych formach na przekształcaniu emocji, pracy na płaszczyznach duchowej i fizycznej traktowanych jako dwa nierozerwalne aspekty tej samej istoty. W tym kontekście można lepiej zrozumieć funkcję dharmapalów, którzy często ukazywani są w gniewnej postaci. W tym miejscu chodzi przede wszystkim o szczególne znaczenie gniewu w praktykach tantrycznych i jego umiejętne wykorzystanie.

[...] dla zwyczajnych ludzi, takich jak my, gniew stanowi intensywną, potężną emocję, która wydaje się sprzyjać pewnym zadaniom. Możemy więc zrozumieć, dlaczego $w$ tantrze Budda zrobił wyjątek, zezwalając na wzbudzanie gniewu - w tantrze bowiem można znaleźć techniki i metody wykorzystywania emocjonalnej energii gniewu, a nawet nienawiści, dla pozytywnych celów. Tutaj jednak musimy być świadomi, że aby wykorzystać nienawiść i gniew w słusznym celu, musimy nieustannie utrzymywać naszą pierwotną motywację: altruistyczną aspirację osiągnięcia oświecenia dla dobra innych. [...] Jeżeli bierze się pod uwagę ów kluczowy element, można również zrozumieć znaczenie gniewnych aspektów bóstw w tantrze (Dalajlama XIV; Jinpa 2015: 103). 
Pełne gniewu bóstwa spełniają więc dwie funkcje: chronią buddyzm, co wynika już z nazwy tej klasy istot, i reprezentują energię negatywnych emocji, którą dzięki praktykom tantrycznym można wykorzystać na ścieżce wiodącej do Oświecenia.

Przyjrzyjmy się pierwszej funkcji Strażników. Ochrona Dharmy może mieć wymiar przestrzenny i duchowy. Wiąże się to z podziałem dharmapalów na dwie kategorie: światowych, których zadaniem jest strzeżenie miejsca, regionu, kraju oraz oświeconych, którzy stanowią gniewne emanacje buddów. Nawiązując do poprzedniego akapitu, należy wyjaśnić znaczenie przymiotnika gniewny w kontekście Oświecenia, co najlepiej uczynią słowa XVII Karmapy Trinleja Taje Dordże [Phrin-las Mtha'-yas Rdo-rje]:

Oświeceni strażnicy są aspektami mądrości Buddy - przykładem może tu być Mahakala. Ich esencja zaś to nieograniczone współczucie - tak samo jak w przypadku Czenreziga. Wielkie współczucie może się wyrazić albo w łagodniej, albo w gniewnej formie. O Mahakali można powiedzieć więc, że jest gniewną manifestacją współczucia. Słowo „gniewny” odnosi się tu tylko do tego, jak on wygląda. Jego aktywność zaś określamy ściśle jako „ochraniającą w pełen mocy sposób”. Oznacza to, że strażnicy działają bez przeszkadzających emocji. W zachodniej kulturze gniewnym jest się jedynie w związku z ego. Tymczasem strażnicy wyrażają się w gniewny sposób nie posiadając ,ja”. Na relatywnym poziomie zwykle ukazują się w gniewnej formie, mogą jednak również manifestować się w lagodnej. [...] aktywnością światowego strażnika jest ochrona rejonu, kraju czy miejsca przed problemami czy szkodliwymi wpływami. Najważniejszą zaś aktywnością strażników Dharmy pozostaje ochranianie nauk. Główne ich działanie nie dotyczy ochrony przed zewnętrznymi zagrożeniami. Strażnicy Dharmy ochraniają nas przede wszystkim przed "wewnętrznymi wrogami” - przeszkadzającymi emocjami, jak przywiązanie, pomieszanie, zazdrość, gniew i duma. To właśnie oni pomagają nam poskromić i kontrolować te słabości. W ten sposób otaczają praktykujących Dharmę ochroną. Poprzez Strażników Dharmy, tak samo jak poprzez inne aspekty Buddy, wyraża się oświecenie w jego trzech właściwościach: mądrości, mocy i współczuciu. Wszyscy posiadamy naturę Buddy, ale żeby ją rozpoznać, potrzebujemy odpowiednich okoliczności. Do zadań strażników należy właśnie tworzenie ich dla nas - chronią nas przed sytuacjami niekorzystnymi dla naszego rozwoju i pomagają znaleźć najlepsze warunki dla rozpoznania naszej wrodzonej natury Buddy. Innymi słowy, energie te usuwają przeszkody z naszej drogi do oświecenia ${ }^{3}$.

Przymiotnik gniewny odnosi się więc tylko do formy, w której Strażnicy są ukazywani, nie do emocji, bowiem dharmapalowie kierują się w swoim działaniu współczuciem - cechą istoty oświeconej. Oprócz protekcji nad miejscami Strażnicy oferują praktykującym również pomoc na płaszczyźnie duchowej

3 Czaja, Paulina, Strażnicy Dharmy. Wywiad z XVII Karmapą Taje Dordże, http:// www.diamentowadroga.pl/dd36/straznicy_dharmy [Dostęp: 21.03.2019]. 
Thanka nr 2, Mahakala,

http://www.thangka.de/Gallery-2/W rathful/5-34/maha-1.htm [Dostęp: 20.04.2019]

Thanka nr 3, Czenrezig-Awalokiteśwara, http://www.thangka.de/Gallery-1/ Bodhisattvas/4-48/Lokeshvar-1.htm [Dostęp: 20.04.2019]
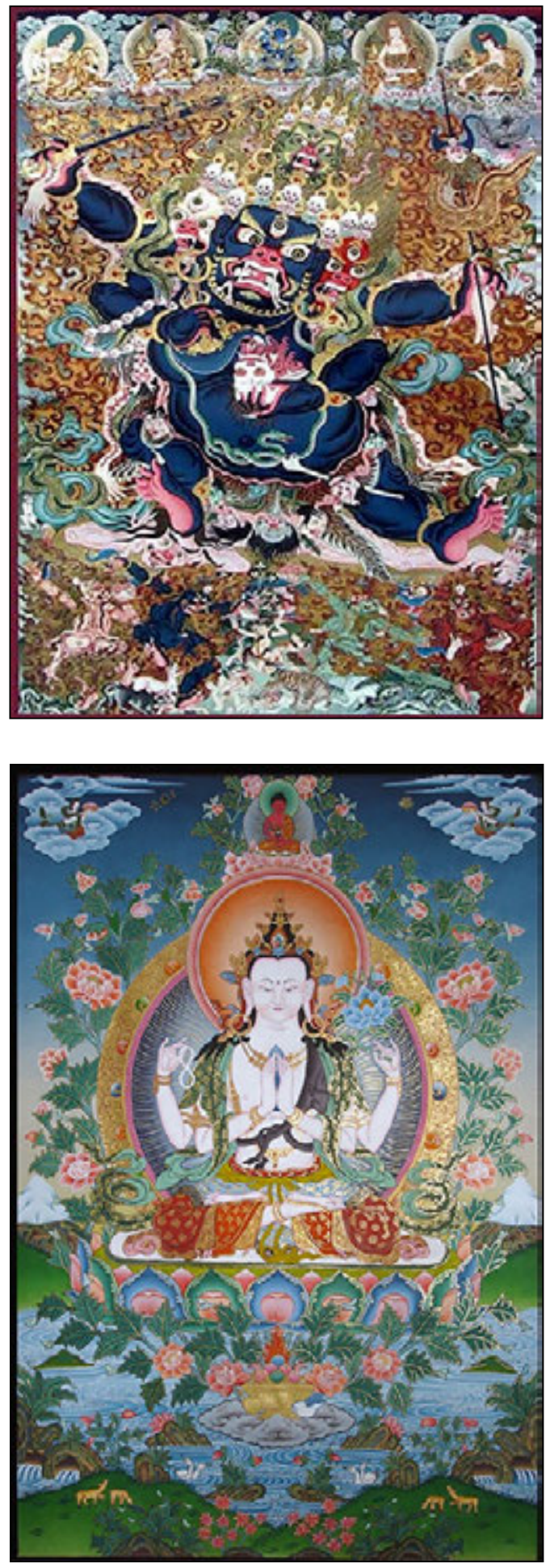
w usuwaniu przeszkadzających uczuć, co jest drugą z wyżej wspomnianych funkcji, bowiem Strażnicy wykorzystują symbolizowany przez nich gniew, by pomóc żywym i czującym istotom aspirującym do osiągnięcia stanu Buddy. Dodatkowo można pokusić się o interpretację gniewnych aspektów buddów jako symbolu aktywności, działania na rzecz oświecenia wszystkich żywych i czujących istot jak przywoływany przez XVII Karmapę Mahakala. Tradycyjne wyobrażenia buddów - jak Czenrezig [spyan-ras-gzigs] - rozumieć można jako ich aspekt pasywny.

Kolejną funkcją dawnych bogów jest udzielanie rad i wskazówek. Mowa tu o wyroczniach będących dziedzictwem szamanizmu bon [bon]. Najważniejszą $\mathrm{z}$ tych instytucji pozostaje państwowa wyrocznia w Neczungu [gNas-chung], której główny kapłan jest medium przedbuddyjskiego bóstwa Pehar [dPe-har]. Od chwili chińskiej inwazji medium znajduje się wraz z Dalajlamą XIV na emigracji. Warto dodać, że wróżbiarstwo i kontakt ze sferą duchów były na tyle ważne, że dawniej niemal każdy klasztor, a nawet wioska posiadały swoje oficjalne wyrocznie (Uhlig 2008: 160-162).

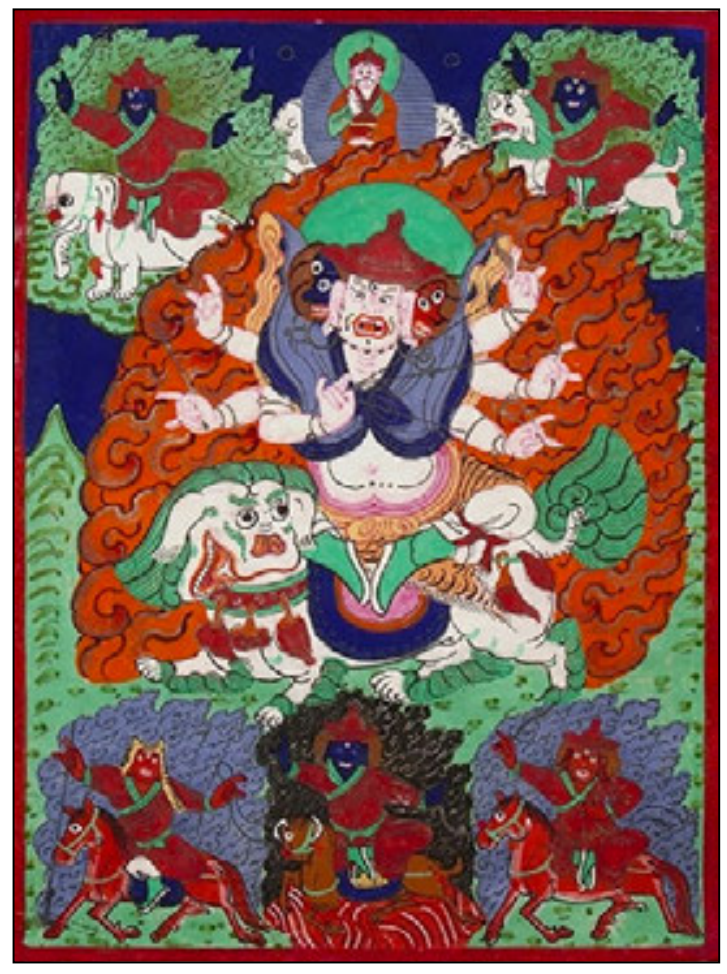

\author{
Thanka nr 4, \\ Pehar, \\ https://www.himalayanart.org/ite \\ $\mathrm{ms} / 94198$ \\ [Dostęp: 20.04.2019]
}

Neczung [gNas-chung] należy uznać za jeden z symboli migracji starych bóstw pod dachy buddyjskich klasztorów. Mamy więc do czynienia ze zjawiskiem dwukierunkowej migracji. Najpierw doszło do napływu nowej religii, która 
wymusiła uchodźstwo swojskich bogów do przybytków Buddy. To wzajemne mieszanie się dwóch tradycji zaowocowało synkretyzmem religijnym - wykształceniem odrębnej gałęzi na szerokim drzewie genealogicznym buddyzmu.

\section{Trzecia migracja - proroctwo guru Padmasambhawy}

W centrum światopoglądu Tybetańczyków stoją religia i tradycja, które akcentują nietrwałość rzeczy i zjawisk zmysłowych. Tym właśnie wytłumaczyć można stulecia oporu, który Tybetańczycy stawiali tyranii przedmiotów, zamykając swoje granice na świat. Co prawda do Tybetu docierały zdobycze zachodniej cywilizacji, jak płyty gramofonowe, aparaty fotograficzne i samochody, jednak dla mieszkańców Himalajów były to tylko ciekawostki z zagranicy, bowiem w myśl filozofii buddyjskiej nie warto poddawać się urokom przemijalnych przedmiotów (Tokarska-Bakir 2014: 15-17).

W pewien sposób zmieniło się to z chwilą chińskiej inwazji na Tybet, w wyniku której od 1959 roku Dalajlama XIV wraz ze swoim najbliższym otoczeniem przebywa na emigracji w Dharamsali w Indiach, a Chińczycy otwierają Himalaje na zdobycze współczesności, budując asfaltowe drogi, lotniska, tory kolejowe, świeckie szkoły i szpitale. Wrota tajemniczego Tybetu zostały otwarte na świat - również świat otworzył się na Tybet - bowiem ludzie, którzy poszli w ślad za Dalajlamą XIV, oferują Zachodowi własną kulturę i tradycję (Uhlig 2008: 6-12).

Wśród Tybetańczyków powszechnie znane jest proroctwo guru Padmasambhawy, według którego „kiedy pofrunie ptak z metalu, a konie potoczą się przed siebie na kołach, wówczas Tybetańczycy rozproszą się po świecie jak mrówki i nauczanie Buddy dotrze do najodleglejszych krajów" (Uhlig 2008: 6-7). Trudno nie zgodzić się z tymi słowami, zwłaszcza w kontekście historii XX i XXI wieku. Emigracja lamów obudziła zainteresowanie buddyzmem w jego himalajskiej odmianie. Także w Polsce działają buddyjskie ośrodki tradycji tybetańskiej.

Na naszych oczach wypełnia się przytoczone proroctwo, które niejako nadaje wyższy sens tybetańskiemu wygnaniu. Powstaje też pytanie, jak doświadczenia emigracyjne ukształtują przyszłe pokolenia Tybetańczyków. Czy wyrzucą ze swoich serc religię i tradycję, które przekształciły ich krewkich koczowniczych przodków w osiadłych mnichów? I w końcu - co czeka sam buddyzm w zetknięciu z Zachodem?

\section{Zakończenie}

Kulturę Tybetu, jak to zaznaczono we wstępie, ukształtował buddyzm, który dzięki protekcji dworu królewskiego ugruntował swoją pozycję do tego stopnia, że od czasów Dalajlamy V jego następcy sprawowali faktyczną, polityczną władzę 
na dachu świata (Uhlig 2008: 78). Migracja nowej wiary zmieniła stosunki społeczno-gospodarcze oraz przysłużyła się kulturze, sztuce i literaturze.

Jednocześnie Tybet nie wyrzekł się swoich dawnych tradycji. Dzięki jednoczącej działalności guru Padmasambhawy rodzime duchy znalazły schronienie w przybytkach Oświeconego, zyskując rolę dharmapalów - protektorów jego nauk, miejsc i wyznawców - lub wypełniając funkcję duchów wróżebnych.

Także dziś jesteśmy świadkami migracji Tybetańczyków uciekających przed chińskim reżimem. Ze swojej ojczyzny położonej na granicy nieba i ziemi, krainy bogów i ludzi unoszą własną kulturę, oferując ją, jak to przepowiedział guru Padmasambhawa, światu.

\section{Bibliografia}

Brauen, Martin, Was sind Thangkas?, http://www.thangka.de/Icono/thangkasgerm.htm [Dostęp: 26.04.2019].

Czaja, Paulina, Strażnicy Dharmy. Wywiad z XVII Karmapą Taje Dordże, http://www.di amentowadroga.pl/dd36/straznicy_dharmy [Dostęp: 21.03.2019].

Dalajlama XIV; Jinpa, Thupten (2015), The World of Tibetan Buddhism. Poznań.

Tokarska-Bakir, Joanna (2014), Wyzwolenie przez zmysty. Tybetańskie koncepcje soteriologiczne. Toruń.

Uhlig, Helmut (2008), Tibet. Ein verbotenes Land öfnet seine Tore. Katowice.

\section{Spis ilustracji}

Thanka nr 1, Guru Padmasambhawa, http://www.thangka.de/Gallery-3/Padma/11-1/ Padma-1.htm [Dostęp: 20/04/2019].

Thanka nr 2, Mahakala, http://www.thangka.de/Gallery-2/Wrathful/5-34/maha-1.ht m [Dostęp: 20.04.2019].

Thanka nr 3, Czenrezig-Awalokiteśwara, http://www.thangka.de/Gallery-1/Bodhisattva s/4-48/Lokeshvar-1.htm [Dostęp: 20.04.2019].

Thanka nr 4, Pehar, https://www.himalayanart.org/items/94198 [Dostęp: 20.04.2019]. 


\title{
Zbigniew Bierzyński \\ Three Migrations. The Short Presentation of The Origins of Buddhism in Tibet And Its Impact on Tibetan Culture With Particular Reference to The Idea of The Dharma Protectors
}

\begin{abstract}
In this article it is assumed that migration (in its literally and metaphorical meaning) had significant impact on the Tibetan spirituality. The main aim of this article is to bring closer figure and function of Dharma Protectors (Sanskrit: dharmapala), whose roots have grown out of the pre-Buddhist times.

The first migration is connected with the origins of Buddhism on the Roof of the World (activity of Guru Padmasambhava, king Songtsen Gampo and his wives Bhrikuti and Wencheng). That has caused the evolution of Himalayan native deities to the Dharma Protectors. This transformation has resulted in the second migration - metaphorical journey of shamanic deities into the Buddhist monasteries. Many legends and myths are telling about it. Their examples are presented and explained shortly.

Finally, the third migration - caused by the Chinese invasion on Tibet - is associated with the mysterious prophesy of Guru Padmasambhava and the question of migration's influence on the future Tibetan generations.
\end{abstract}

Keywords: migration, Buddhism, dharmapala, impact, Dharma Protector, Tibet Słowa kluczowe: migracja, buddyzm, dharmapala, wpływ, Strażnik Dharmy, Tybet 